\title{
A teoria marxista da dependência: papel e lugar das ciências sociais da Universidade de Brasília
}

Recebido: 11.11 .16

Aprovado: 30.01 .17
Sadi Dal Rosso

\& Raphael Lana Seabra*

Resumo: Propõe-se, neste artigo, analisar a contribuição da produção social de quatro intelectuais que trabalharam nos primórdios da Universidade de Brasília com relação à teoria marxista da dependência. São utilizados textos e memoriais produzidos à época e duas entrevistas realizadas recentemente, além da bibliografia sobre o assunto. Encontrou-se evidência de que a Universidade de Brasília foi lugar de embate teórico travado entre funcionalismo e marxismo, da necessidade de fundamentar a produção analítica dos intelectuais com o aporte metodológico e teórico do marxismo, da realização da crítica sobre a concepção da relação entre países que fazem parte do sistema mundial como desenvolvidos e subdesenvolvidos, sem com isso envolver uma relação de exploração, embora se tenha encontrado nos textos referências e raízes de elementos da teoria da dependência, tal como o mecanismo da exploração redobrada pela burguesia nacional e pelo capital internacional. O artigo destaca a formação militante de pelo menos três dos quatro intelectuais nas fileiras da Organização Revolucionária Marxista - Política Operária (Polop) e sua influência sobre a atuação política e a necessidade da revolução socialista.

Palavras-chave: teoria marxista da dependência, desenvolvimento, subdesenvolvimento, império, Universidade de Brasília.

\section{Introdução}

A teoria da dependência ocupa espaço de relevância no debate acadêmico brasileiro, latino-americano e mundial desde sua formulação, há quase meio século. Nas duas últimas décadas, é notável no meio universitário o resgate e a divulgação de obras de seus principais autores, como Ruy Mauro Marini, Theotônio dos Santos, Vânia Bambirra e Andre Gunder Frank ${ }^{1}$. Tal retomada da teoria da dependência abre um novo marco de reconsideração e interpretação de seus principais elementos teóricos e analíticos para o estudo do desenvolvimento capitalista. Veem-se cada vez mais trabalhos de conclusão de cursos de graduação, dissertações de mestrado, teses de doutorado, artigos e livros assumirem proposições teóricas da dependência como elementos de base para a análise sociológica contemporânea.

Na maioria dos trabalhos sobre a teoria da dependência, enfatiza-se seu desenvolvimento chileno, mais especificamente no Centro de Estudos Socioeconômicos

\author{
* Sadi Dal Rosso \\ é professor do \\ Departamento \\ de Sociologia \\ da Universidade \\ de Brasília. \\ <sadidalrosso@ \\ gmail.com>. Raphael \\ Lana Seabra é doutor \\ em sociologia pela \\ Universidade de \\ Brasília e autor/ \\ organizador de \\ Dependência \\ e Marxismo: \\ contribuição ao \\ debate crítico latino- \\ americano. \\ <raphaelseabra@ \\ hotmail.com>. \\ 1. Um importante \\ marco para este \\ resgate e reavaliação \\ foi a publicação \\ de Dialética da \\ dependência, de Ruy \\ Mauro Marini, sob \\ a organização Emir \\ Sader, em 2000
}


(Ceso) da Universidade do Chile, e posteriormente no México, momento em que esta contribuição alcançou maior visibilidade nas ciências sociais mundiais (Palma, 1987; Kay, 1989; Larrain, 1998). Ora, na trajetória histórica da teoria da dependência, ocorreu um momento em que importantes nomes responsáveis pela teoria encontraram-se e conviveram durante praticamente dois anos na Universidade de Brasília. Donde emerge a pergunta sobre o papel que teria preenchido - se houve algum - a presença desses intelectuais nessa universidade no processo de construção daquela teoria. Este aspecto dos estudos sobre a teoria da dependência ainda não foi explorado por pesquisadores sociais, tanto quanto está ao alcance de nosso conhecimento, de modo que se converte em interessante objeto de investigação. A publicação de um dossiê sobre os caminhos percorridos pela sociologia na Universidade de Brasília através da revista Sociedade e Estado oferece a oportunidade para esquadrinhar a trajetória da pesquisa sobre tal questão.

Nosso entendimento provisório é de que seria muito difícil imaginar que quatro intelectuais do porte dos integrantes da teoria da dependência ter-se-iam encontrado e convivido durante dois anos sem que nada tivessem aportado à formulação teórica das relações entre países centrais e periféricos, ainda que de forma embrionária. Seriam ideias, propostas, análises e interpretações tais como raízes de uma formulação sistemática que se consolida posteriormente, em períodos mais longos de permanência no Chile e no México, junto a um coletivo de colaboradores muito mais expressivo e diversificado. Tal qual uma árvore não pode ser impunemente podada de suas raízes, assim também uma formulação teórica.

O objetivo principal deste artigo é, pois, contribuir para o conhecimento dessas raízes durante o curto período de dois anos durante os quais estes jovens intelectuais estiveram na Universidade de Brasília. Para tal empreitada lançamos mão de elementos desenvolvidos durante sua permanência na Universidade de Brasília e que podem ser encontrados sob a forma de livros, artigos, teses de mestrado, memoriais escritos pelos próprios autores e duas entrevistas realizadas, uma com Theotônio dos Santos, outra com Vânia Bambirra. Como alguns desses materiais não estão inteiramente disponíveis - a tese de mestrado de Ruy Mauro Marini teria sido destruída durante a invasão militar da UnB, em 1964, bem como artigos redigidos para revistas de circulação de massa, jornais e panfletos não estão disponíveis -, nosso artigo assume um caráter de estudo inicial sobre o tema, podendo ser modificado à medida que novos elementos sejam descobertos. Além dessas primárias fontes mencionadas, já existe uma bibliografia relativamente extensa e crescente em número sobre a história da teoria marxista da dependência, a qual incide sobre o período anterior e posterior à passagem, nada porém sobre a estada do "grupo dos quatro" na Universidade de Brasília, representando um vazio de conhecimento. 
Antes de dar início ao objeto do artigo propriamente dito, fazemos menção a aspectos do contexto social em que ocorreu a participação dos formuladores da teoria da dependência na Universidade de Brasília. Um deles é de caráter mais pessoal e individual, como é o caso da juventude de nossos sujeitos, que permite uma inserção na relação entre sujeito e estrutura. Em segundo lugar, o projeto da Universidade de Brasília, que é de caráter mais institucional e político, e, por último, o contexto sociopolítico nacional e internacional no qual estão imersos os autores e o Brasil como um todo, novamente propiciando uma entrada na relação dos sujeitos com a história em formação.

\section{A formação de uma sociologia militante: \\ a Organização Revolucionária Marxista - Política Operária e a Universidade de Brasília}

Que a teoria marxista da dependência tenha iniciado seu desenvolvimento no Brasil não foi fruto do acaso, sobretudo se levarmos em conta que as principais referências desta corrente ainda são o "grupo dos quatro". Deste modo, é importante levantar três fontes determinantes para sua formação no país: a primeira deve-se ao ambiente político e intelectualmente instigante de combate às concepções liberais, que abriram espaço para o debate público sobre a modernização e o desenvolvimento, cujo centro irradiador era Instituto Superior de Estudos Brasileiros (Iseb), fundado durante o governo do presidente Juscelino Kubitschek, em 1955; a segunda, o aprofundamento das críticas provenientes de círculos intelectuais radicais aos partidos que até então polarizaram as esquerdas no país, como o Partido Comunista Brasileiro (PCB) e o Partido Trabalhista Brasileiro (PTB), o desgosto com a crise do movimento comunista internacional devido ao informe de Nikita Kruschev sobre os crimes de Stalin e o impacto causado pela Revolução Cubana de 1959; por fim, como país de maior desenvolvimento do capitalismo dependente na América Latina, suas contradições se apresentaram mais rapidamente e mais profundas ao final dos anos 1950, fatos que levaram à ruptura do regime democrático e a instauração da ditadura militar como novo modelo de dominação burguesa na década seguinte. Essas condições geraram uma fecunda luta político-ideológica que buscou superar os esquemas teóricos até então hegemônicos, como também conduziram à gestação de novas organizações políticas de esquerda.

Neste contexto, surge a Esquerda Revolucionária, definição que abrange o conjunto de grupos ou organizações que, em resposta ao reformismo do PCB e do PTB, adotam como denominador comum o caminho da insurreição como única via para a revolução. Rompe-se a tese política de conciliação com as frações industriais da 
2. Não é possível repassar em detalhes as características de cada organização, assim, consideramos válida a divisão estabelecida por Bambirra (1972, p. 52-71) em próchineses, foquistas e a nova esquerda. A Política Operária situa-se na última vertente.

3. Militante da Oposição Comunista Alemã e fugitivo da perseguição nazista, Eric Sachs foi naturalizado brasileiro em fins dos anos 1930. Eric escreveria sob os pseudônimos Eurico Mendes e, mais recorrentemente, Ernesto Martins. burguesia e reivindica-se a plena autonomia organizativa e política do movimento proletário frente à burguesia. A maioria dos grupos, organizações e partidos da Esquerda Revolucionária postulavam a falta de vocação revolucionária da burguesia brasileira. Não havia caminho gradual e pacífico para o socialismo (Bambirra, 1972; Reis Filho, 2007). Todavia, existia nessas organizações diferenças substanciais em relação à definição da natureza da revolução, o modo de conceber as formas de insurreição, como também o sujeito da revolução².

A tarefa de fazer circular a imperiosidade de renovação do campo de esquerda e de articular esse campo no sentido da construção de uma alternativa foi dirigida pelo militante austríaco Eric Sachs ${ }^{3}$ desde a publicação, em 1959, da revista O Movimento Socialista. Essa publicação obteve certa repercussão, atraindo grupos dissidentes do trabalhismo em Minas Gerais, o grupo luxemburguista Liga Socialista Independente de São Paulo e a Juventude Socialista do Partido Socialista Brasileiro (PSB) do Rio de Janeiro, além de outros militantes independentes.

A partir da recepção positiva da revista e da ampliação dos contatos, foi lançada a convocatória, em julho de 1960, para o I Congresso da Polop que ocorreria em fevereiro de 1961, no interior de São Paulo. As teses da nova organização eram influenciadas por referências diversas, desde Nikolai Bukharin, Rosa Luxemburgo, Franz Mehring e Vladmir Lenin, até intelectuais menos conhecidos no Brasil como dois militantes da Liga Espartakista alemã Heinrich Brandler e August Talheimer, inspiradores do ideário da Oposição Comunista Alemã antistalinista e caracterizada por sua autonomia criadora de uma elaboração original (Meyer, 2009).

Sua militância era formada por estudantes, militares de baixa patente e, em menor número, por operários industriais, mas com claro predomínio de intelectuais (Mattos, 2007). De acordo com Marini (1971: 133), sem dispor de aparatos armados e carente de uma base proletária significativa, a organização buscou amparar-se em seus princípios, em sua capacidade de produção teórica para lograr se afirmar no seio da esquerda. Esse fato levantou uma série de críticas ao suposto intelectualismo da organização, porém a maior limitação da organização para favorecer a aglutinação da Esquerda Revolucionária resultou, principalmente, de sua incapacidade de aprofundar seus acertos teóricos e convertê-los em estratégia global de ação, que respondesse às exigências da luta de classes em nível político e militar.

A Polop instaura, através de suas circulares documentos de debate e o próprio programa político, um novo marco de interpretação do desenvolvimento capitalista brasileiro: a identificação do caráter capitalista da sociedade brasileira, e que nesse sentido a revolução brasileira não demandaria a "realização" e a "superação" de 
etapas históricas de transição, senão que caminharia diretamente ao socialismo; a defesa consistente de que não haveria possibilidade da reprodução de experiências estrangeiras para a superação do subdesenvolvimento brasileiro, seja a reprodução do capitalismo central, sejam as experiências socialistas; através do uso original do marxismo como meio de aprofundar a conceituação e compreensão da dinâmica histórica do capitalismo brasileiro, assim, a organização desenvolve uma análise dialética entre a vinculação subordinada brasileira ao mercado mundial e aos interesses dos países imperialistas (Mattos, 2007; Polop, 2009; Leal, 2014).

A síntese expositiva sobre a Polop é fundamental, uma vez que contesta as interpretações correntes que colocam a teoria da dependência meramente como subproduto e alternativa acadêmica à teoria desenvolvimentista da Comissão Econômica para América Latina e Caribe (Cepal). Para Ruy Mauro Marini, as raízes da vertente marxista da teoria da dependência estão

\footnotetext{
nas concepções que a "Nova Esquerda" - particularmente no Brasil, embora seu desenvolvimento político fosse maior em Cuba, na Venezuela e no Peru - elaborou, para fazer frente à ideologia dos partidos comunistas (Marini, 1971: 66).
}

A Cepal só se converteria em alvo no momento em que os comunistas passaram a apoiar as teses desenvolvimentistas para sustentar sua estratégia etapista da revolução. Vânia Bambirra também defende o papel da Polop para a conformação de uma visão alternativa, posto que na

Política Operária, tratou-se de desenvolver estas teses na busca de uma fundamentação mais sólida para contra-arrestar os argumentos que defendiam a aliança de classes preconizada pelo Partido Comunista e que havia sido levada à prática no governo de Goulart (Bambirra, 1983: 21).

Não há qualquer demérito na relação simbiótica entre as formulações teórico-políticas polopistas e aquelas que virão a ser conhecidas posteriormente como teoria marxista da dependência. Sem dúvidas, os manifestos, as resoluções e os programas dos partidos de esquerda constituem um tipo de produção intelectual distinto da produção acadêmica, principalmente por não seguir os mesmos padrões formais, tais como a "neutralidade axiológica". É tão verdadeiro que esse conhecimento produzido no meio militante se aproprie de metodologias e teorias das ciências sociais, como também o inverso. Desse modo, enquanto uma organização política pressupõe quadros que falem a mesma linguagem comum e tenham maior nível de centralização, a novel Universidade de Brasília, sem perder de vistas a imperiosidade 
4. "O instrutor não estava na carreira universitária, era estudante de pós-graduação, fazia cursos especializados, trabalhava uma tese de mestrado e recebia um salário para auxiliar no ensino", escreve Roberto A. Salmeron (2007: 90).

5. “A Universidade de Brasília inaugurou seus cursos no dia 9 de abril de 1962, em salas emprestadas pelo Ministério da Educação e Cultura", escreve mais uma vez Salmeron (2007: 99).

6. As fundações já eram amplamente utilizadas nos Estados Unidos e de lá foram importadas como proposta modernizante de organizar as universidades institucionalmente, com mais autonomia frente aos governos, mas também com maior interferência do setor privado em seu conselho diretor.

7. “Então, ele [Darcy Ribeiro, o reitor] me chamou e falou: Vânia, o Theotônio já é daqui e você agora tá vindo, vocês vão se enriquecer às custas da Universidade... então, eu vou cortar o seu salário pela metade. (Vânia) Ah, mas eu virei uma arara e o que salvou ele... foi para a Casa Civil... senão ia fazer greve e derrubar ele, porque ninguém tava satisfeito com isso" (Entrevista com Vânia Bambirra, 2013: 29). de superar o subdesenvolvimento, foi fundamental como espaço crítico, inovador, produtor de conhecimentos científicos. A Fundação da Universidade de Brasília, em 1962, acabará reunindo alguns intelectuais destacados que se formaram sob a influência do desenvolvimentismo, embora não diretamente ligados a ele (Dos Santos, 1991: 26).

"Instrutores", assim eram denominados os professores iniciantes na carreira, recém-contratados pela Universidade de Brasília para ensinar, pesquisar e realizar extensão de conhecimentos ${ }^{4}$. Os "instrutores" de que trata este artigo eram extremamente jovens, por volta dos 20 e 30 anos de vida, tendo elaborado ou estando em preparação de dissertações de mestrado e teses de doutorado. Pela juventude, não se pode exigir produção teórica além do que ela permite, ao mesmo tempo, é a etapa da vida que possibilita grandes envolvimentos pessoais e sociais emocionantes. O primeiro a chegar, em 1962, foi Theotônio dos Santos, seguido posteriormente de sua esposa, Vânia Bambirra, e de Ruy Mauro Marini, todos integrados ao curso de graduação em ciência política e à pós-graduação em ideologia brasileira. Em 1963, André Gunder Frank é integrado ao Instituto de ciências sociais como professor convidado por Darcy Ribeiro.

A Universidade de Brasília, instituição que os acolheu, estava em seu início ${ }^{5}$ e se propunha um projeto inovador ao enfatizar as atividades de pesquisa, dar importância à relação entre universidade e sociedade por meio dos cursos de extensão, ao colocar os temas nacionais e internacionais entre os compromissos dos docentes e ao dar início a outra forma institucional, a fundação ${ }^{6}$. Como a universidade estava começando, instrutores e professores tinham ampla liberdade de organizar os programas letivos e de desenvolver atividades extracurriculares.

É curioso o fato de que um intelectual progressista como Darcy Ribeiro tenha protagonizado um episódio de claro machismo em relação à Vânia Bambirra. Quando integrada como docente da universidade, Ribeiro se "esforçou" por convencer Bambirra de que, por ser mulher, sua remuneração deveria ser inferior à de seu marido Theotônio dos Santos. Este ocorrido fez com que Bambirra se mobilizasse, denunciasse o machismo de Ribeiro, ameaçasse com greve e lançasse a ideia da fundação de uma associação ou sindicato para defender os professores, ideia que precede em quinze anos a criação da Associação dos Docentes da Universidade de Brasília (ADUnB), logrando reverter a imposição e perspectiva de Darcy Ribeiro ${ }^{7}$. Como parte do objetivo de construir um pensamento próprio sobre o Brasil e sobre a região, Dos Santos em entrevista ${ }^{8}$ levanta a informação de que Darcy Ribeiro firmou contrato com a Cepal através de seu instituto subsidiário, o Instituto Latino-Americano de Planificação Econômica e Social (Ilpes), para que ministrasse um curso trimestral 
sobre teoria do desenvolvimento. Isso proporcionou maior contato desse grupo de jovens professores com o que havia de mais avançado nas ciências sociais da época. Outra iniciativa tomada pelo grupo de professores participantes do Instituto de Ciências Sociais consistiu na organização de um seminário contínuo de leitura de $O$ Capital, de Marx, acompanhando experiências em vários outros lugares, seja de Paris, seja da Universidade de São Paulo. Participaram do seminário um grupo grande de professores e instrutores entre os quais Teothônio dos Santos, Vânia Bambirra, Ruy M. Marini, Perseu Abramo e José Albertino Rodrigues (Dos Santos, 2013: 4-5).

A presença de André Gunder Frank tem importância significativa, dado seu contato com grupo da revista marxista norte-americana Monthly Review, dirigida por Paul Baran, Leo Huberman e Paul Sweezy. Mas também por sua formação na Escola de Chicago, o que permitiu que ministrasse seminário e curso sobre o pensamento estrutural-funcionalista nas ciências sociais norte-americanas para os jovens "instrutores". Quando de sua chegada à UnB, Frank já havia começado sua ruptura com a referida escola, principalmente pela percepção da aversão que o grupo de Chicago tinha à teoria do desenvolvimento, mas também muito impactado pela Revolução Cubana durante sua breve passagem pelo México, em 1962 (Frank, 1991).

A criação da Universidade de Brasília é um elemento chave para o entendimento da construção da teoria marxista da dependência. Importantes universidades públicas já existiam nas capitais dos estados: a Universidade de São Paulo (USP), a Universidade Federal do Rio de Janeiro (UFRJ), a Universidade Federal de Minas Gerais (UFMG), a Universidade Federal do Rio Grande do Sul (UFRGS) e tantas outras. Entretanto, somente a Universidade de Brasília foi capaz de reunir tantos intelectuais em um mesmo lugar, na mesma época, trabalhando num projeto coletivo. O que seria capaz de atrair tantos quadros? Uma fundação universitária com um projeto aberto para a discussão dos problemas nacionais e internacionais, com liberdade de ensino, pesquisa e iniciativas acadêmicas, tais e outras condições em conjunto foram responsáveis por reunir intelectuais e colocá-los a trabalhar em um plano. Theotônio dos Santos analisa com amplidão o projeto da Universidade de Brasília que conseguiu reunir tantos intelectuais:

A universidade de Brasília não era "mais uma" universidade, ela era a ideia da nova universidade que colocaria o Brasil no plano internacional, realmente entre os grandes centros de conhecimento, dos grandes centros de produção do conhecimento, mas não só de conhecimento, mas de produção de artes também, afinal o próprio projetista da universidade... vai dar à universidade uma personalidade muito forte na sua concepção arquitetônica... Nas ciências sociais o grupo é muito forte... Era uma universidade que
8. Com o apoio da Comissão UnB 50 anos - História e Futuro, Sadi Dal Rosso, professor do Departamento de Sociologia da Universidade de Brasília, no intuito de resgatar a importância das ciências sociais da UnB, entrevistou Theotônio dos Santos e Vânia Bambirra. 
reunia o melhor que pudesse... para desenvolver a universidade, com um concepção pedagógica nova, muito flexível, um trabalho mais de equipe... então todos nós estávamos ali com a ideia de que estávamos criando uma coisa nova. Ali se inicia também a ideia dos cursos de extensão... com várias modalidades de contato com a população... o trabalho de pesquisa... com grande participação dos alunos... Era um laboratório fantástico. Infelizmente o golpe de Estado... em 1964 os militares invadiram a universidade em busca de armas e as únicas que encontraram foram abridores de livros (Dos Santos, 2013: 3-4).

Condições análogas para o trabalho acadêmico foram encontradas mais tarde no Centro de Estudios Socio-Económico (Ceso) da Universidade do Chile e, então, foi retomado com ainda mais vigor - porquanto a equipe era muito maior, mais diversificada internacionalmente e com maior sistematicidade - o projeto da teoria da dependência. Vale também acentuar que Santiago era sede de desenvolvimento do pensamento crítico cepalino.

Sendo assim, a mescla entre a análise empírica e teórica dos jovens instrutores provenientes da Polop, com o ambiente pedagógica e intelectualmente instigante da nova universidade, a preocupação vigente entre professores e instrutores pelos temas do imperialismo, do desenvolvimento e subdesenvolvimento e da dependência, comprovam que, naqueles breves anos, a UnB seguiu sua vocação mais ampla como universidade ao submeter todas as verdades à crítica impiedosa e criadora.

\section{Theotônio dos Santos:}

\section{a centralidade da UnB para a teoria da dependência}

Dentre os quatro autores, Theotônio dos Santos foi o primeiro a chegar à Universidade de Brasília, em 1962, aos 26 anos, sendo integrado como mestrando instrutor. Havia se formado um ano antes em sociologia e política, e ainda em administração pública, pela UFMG, e, como militante da Polop, trazia em sua bagagem a imperiosidade de aplicar originalmente o marxismo à realidade brasileira, como também as influências nacionalistas do Iseb, mais especificamente de Alberto Guerreiro Ramos. Em seu memorial apresentado à UnB, em 1994, Theotônio dos Santos é direto sobre a centralidade da universidade para o desenvolvimento da teoria marxista da dependência:

A UnB foi uma experiência extremamente rica no campo pedagógico, mas também pelo contato com o que havia de mais ousado na intelectualidade brasileira. Foi na UnB também que conheci André Gunder Frank e iniciamos sistematicamente uma colaboração de décadas com Ruy Mauro Marini que junto com minha então espo- 
sa Vânia Bambirra formamos um trio polemizado no mundo inteiro (Dos Santos, 1994: 21).

Para Dos Santos, a UnB foi fundamental para dar início ao projeto da teoria marxista da dependência, ainda que seus resultados futuros jamais tivessem sido imaginados por qualquer dos integrantes. O autor reafirma em entrevista que

na Universidade de Brasília, o grupo [Frank, Marini, Bambirra e Dos Santos] se desenvolve em conjunto e depois vamos nos reencontrar no Chile com o André outra vez e dar continuidade ao tipo de problemática que a gente já desenvolvia aqui (Dos Santos, 2013: 6).

Como paralelo entre as universidades de Brasília e do Chile está o ambiente acadêmico que reuniu problemas cruciais de âmbito nacional e internacional; ambos os países passaram por processos políticos em que o enfrentamento de classes terminou com golpe de Estado e destruição dos projetos teóricos em andamento, perseguição e fuga dos intelectuais envolvidos.

Theotônio dos Santos relata que o seminário de leitura de O Capital, ainda que de curta duração,

permitiu avançar no marxismo nas suas formas originais porque muitos já tinham trabalhado outros textos... eu tinha trabalhado quase toda a obra de Marx, o Ruy, a Vânia tinha(m) um vasto conhecimento. O resto do grupo também (Dos Santos, 2013: 5).

Destacamos como peça importante de sua passagem pela UnB a obra Quais são os inimigos do povo, de 1962, o primeiro livro publicado por Dos Santos. Compunha um dos números da coletânea "Cadernos do Povo Brasileiro", era o desdobramento de sua dissertação de mestrado defendida na UnB no mesmo ano, "As classes sociais no Brasil: primeira parte - os proprietários"9. O texto apresenta uma análise das classes sociais no Brasil, com linguagem clara, popular e didática sobre os componentes essenciais da complexa estrutura das classes sociais no Brasil. Sua análise é instigante ao desconstruir a noção de "povo" apropriada tanto pelo reformismo como pelo desenvolvimentismo. Sua concepção de povo remete à construção polopista de Frente dos trabalhadores da cidade e do campo, de modo que o povo seria composto por operários e assalariados em geral, camponeses, estudantes, intelectuais e pequenos proprietários. Essa concepção genericamente é convocada por algumas frações da burguesia sob o manto do nacionalismo, todavia, no momento em que as contradições se acirram e o movimento popular tende à autonomia político-reivindicativa, a noção de povo demonstra seus cortes

\footnotetext{
9. O autor aponta mais um fio da continuidade do projeto iniciado na UnB e aquele efetivado no Ceso:

"Retomei este tema em 1966-1967 quando cheguei ao Chile e realizei um seminário de um semestre no Centro de Estudos Socioeconômicos sobre 'O conceito de classe social'" (Dos Santos, 1994: 24).
} 
internos em classes sociais antagônicas. Deste modo, a burguesia é apresentada em suas frações, interesses específicos e suas relações internas de oposição-associação, dividida em frações: imperialista, latifundiária, comercial (açambarcadores e especuladores), financeira (banqueiros e financistas), e grandes industriais.

Como na primeira obra do autor não é possível encontrar ainda o conceito de dependência, suas referências ainda são ao subdesenvolvimento, ao atraso, à dominação imperialista, à aliança com o capital internacional, à troca desigual e ao sistema colonial. Mas o texto rechaça qualquer esboço de feudalismo ou semifeudalismo no país, defende ao final o caráter já socialista da revolução, faz a crítica às concepções sobre a suposta neutralidade do Estado nacional-desenvolvimentista, e coloca em cena uma das marcas características da teoria marxista da dependência: a associação de interesses entre capital nacional e capital imperialista, quer dizer, a necessidade da análise integrada dos níveis interno e externo para a compreensão da dinâmica do capitalismo brasileiro. Vale a leitura do trecho abaixo:

Assim considerando, pergunta-se, é necessário o capital estrangeiro? Podemos responder que, para o sistema econômico dominado pela burguesia, isto é, pelos grandes grupos e a livre empresa, ele é de fato necessário, na medida em que supre às suas demandas. Ao mesmo tempo é prejudicial a esta mesma classe e, principalmente, ao povo, na medida em que submete nossa economia aos interesses do imperialismo internacional (Dos Santos, 1962: 44).

10. "Na nova forma de dependência - a tecnológicaindustrial $[\ldots]-$, a produção industrial que se desenvolve se encontra condicionada de várias maneiras pelas exigências do mercado internacional de bens e capitais" (Dos Santos, 1973: 51). ausência de técnica e capitais nacionais, assim como de um aparelho estatal que planificasse efetivamente o desenvolvimento e enfrentasse os interesses do imperialismo [...] [deste modo,] esta nova fase do desenvolvimento foi feita em estreita aliança com o capital internacional que passou a controlar vastos ramos de nossa indústria (Dos Santos, 1962: 98-99).

Ainda que de modo simplificado e exploratório vemos aqui a origem da nova dependência ${ }^{10}$. 


\section{Vânia Bambirra: \\ a UnB como fonte da teoria marxista da dependência}

Além de Marta Harnecker, Vânia Bambirra é uma das poucas mulheres que é apresentada como participante formal da construção da teoria marxista da dependência e que pode falar das raízes durante a breve passagem pela Universidade de Brasília, entre 1963 e 1964, espaços tão dominados pelo sexo masculino. Analisar sua contribuição apresenta a dupla vantagem de revelar o olhar feminino sobre a teoria da dependência e sobre o lugar das mulheres na revolução e na construção do socialismo.

Bambirra chega à UnB em 1963, aos 23 anos, aprovada como mestranda instrutora no Departamento de Sociologia. É difícil recolher a produção intelectual desta parte de sua vida, pois sua pouca idade ainda não havia Ihe permitido reflexões mais acabadas, como também seu mestrado fora interrompido pelo golpe civil-militar de abril de 1964. A análise, pois, empregará inicialmente materiais obtidos em seu memorial e por entrevista formal com a autora ${ }^{11}$. Durante a entrevista, Vânia foi indagada sobre o papel da Universidade de Brasília no desenvolvimento da teoria da dependência e ela assim se posicionou:

E a gente então começou, era um grupo grande, era muita gente envolvida... nós começamos [a estudar O Capital]... Fomos interrompidos pelo golpe... A ideia da teoria da dependência não tinha desabrochado. Claro que nas teses da Polop já havia, já se percebia, já estava anotado que as burguesias nacionais eram vinculadas ao imperialismo, a ideia da classe dominante dominada, que a gente vai desenvolver depois no Chile... Eu me lembro que você me perguntou pelo telefone... se por acaso a teoria da dependência tinha surgido na UnB. Eu digo que não, que realmente ela desabrochou, a equipe mesmo... foi composta na Faculdade de Economia da Universidade do Chile e no Centro de Estudios Socio-Económico (Ceso) (Bambirra, 2013: 32).
11. A entrevista foi realizada por Sadi Dal Rosso, em 19 de outubro de 2013 com apoio do projeto Comissão UnB 50 anos-História e Futuro, a quem o entrevistador agradece.

12. O capitalismo dependente latinoamericano foi resultado do grupo de trabalho do Ceso, sob a direção de Theotônio dos Santos, e publicado no Chile, em 1972.

Como se supunha, a entrevistada é peremptória em afirmar - "Eu digo que não" em resposta ao questionamento sobre a teoria da dependência ter desabrochado na Universidade de Brasília, principalmente se considerarmos que sua obra mais divulgada só seria redigida em $1970^{12}$. Mais adiante, a entrevista retorna ao tema com a pergunta refeita da seguinte maneira: "O que resultou teoricamente desse grupo de estudos na UnB? Houve algum acúmulo relevante?" E Vânia responde cheia de dúvidas: "Não... não... formação... nem chegou a tanto porque ficou muito no começo, veio o golpe logo" (Bambirra, 2013: 34-35). 
Então o grupo de estudos de O Capital teve vida muito breve, não permitindo o amadurecimento e o acúmulo da discussão, em razão do golpe de Estado desfechado em abril de 1964.

Tal afirmação não encerra a questão sobre o papel da universidade, uma vez que Vânia permaneceu mais de um ano - entre 1963 e 1964 - trabalhando na universidade que facultava um ambiente propício à discussão das relações entre desenvolvimento e subdesenvolvimento, discussão encabeçada por André Gunder Frank, entre outros que faziam parte do quadro universitário, além do debate estimulado pelo curso da Cepal aí realizado.

Há um aspecto da revolução socialista e, consequentemente, da teoria da dependência, pouco explorado na biografia de Vânia. Trata-se de sua defesa da mulher e tentativa de analisar a mulher na revolução socialista. Esta questão, que certamente já fora despertada nos cursos universitários, aprofunda-se com a relação conflituosa com André Gunder Frank, na Universidade de Brasília. Fala Vânia:

[André Gunder Frank] era norte-americano e conservador... Depois desta questão de dizer que no Brasil tinha latifúndio, a gente sempre caiu em cima dele... Eu tinha brigas homéricas com o Frank. Eu pessoalmente não gostava dele, tinha um certo asco com o Gunder Frank (Entrevista com Vânia Bambirra, 2013: 37-38).

13. Enquanto em várias de suas obras Frank deixa a entender que o salto de qualidade entre a condição colonial para a dependência é quase insignificante, para Bambirra este salto de qualidade se deve não apenas à mudança na condição da formalidade da independência, mas também à própria dinâmica do desenvolvimento capitalista mundial, da passagem da predominância do capital mercantil para o industrial, tornando mais complexa a integração das novas nações dependentes à divisão internacional do trabalho.
A relação era conflituosa por razões teóricas acerca do entendimento sobre a dinâmica complexa entre a estrutura fundiária e a integração do Brasil ao sistema mundial capitalista ${ }^{13}$, a raiz funcionalista de Frank, e em razão das relações de gênero entre homem e mulher. Esta última questão iniciada na Universidade de Brasília continua a martelar a cabeça da autora quando já no Chile, rumo a um processo revolucionário, escreveu um artigo que tem por título "La mujer chilena en la transición al socialismo". O artigo é emoldurado por uma frase de Lenin pela incorporação das mulheres no serviço público, na milícia e na vida política, e que, sem arrancar a mulher do lar, não se chega à liberdade, à democracia e ao socialismo, mas é propiciado concretamente pela realização de uma assembleia das mulheres comunistas do Chile, ocasião que lhe permite suscitar um número de questões sobre o papel da mulher. Desenvolve uma parte histórica sobre o processo de conquista dos direitos civis para a mulher. A partir daí analisa a situação concreta da mulher nos países desenvolvidos e nos países dependentes, aprofunda a situação da mulher no Chile, enaltecendo as conquistas já realizadas. Reconhece o papel da mulher na política e como isso ainda significa pouco para as camadas jovens. Analisa a situação da dona de casa até chegar à mulher independente.

A mulher "independente" é que com família ou sem família não está subjugada à condição de dona de casa; tem independência 
econômica e é capaz de decidir por si mesma sobre sua atuação nos diversos níveis sociais dos quais participa (Bambirra, 1971: 6).

Com esta perspectiva de la mujer independiente lança perguntas sobre o significado da palavra de ordem de Che Guevara a respeito da tarefa de criação de um homem novo.

O conteúdo geral desta tarefa [...] supõe a liberação do homem - no sentido de ser humano - de suas limitações mais agudas, materiais e morais (Bambirra, 1971: 7),

e aí prossegue na discussão de estratégias e de táticas. O artigo é importante não só por ter sido escrito por uma mulher, mas ainda por dirigir-se a elas com propostas libertárias. Mantém a mesma posição coerente no agir e pensar daquela jovem que, recém-chegada à Universidade de Brasília, foi capaz de enfrentar o machismo dos intelectuais.

\section{André Gunder Frank:}

\section{a Universidade de Brasília e a intuição sobre desenvolvimento do subdesenvolvimento}

André Gunder Frank tinha 33 anos ao chegar à Universidade de Brasília, em 1963. Embora jovem, já era uma figura relativamente polêmica e conhecida no meio intelectual norte-americano. Tanto que fora indicado a Darcy Ribeiro pelo antropólogo Eric Wolf. Estudou economia na Universidade de Chicago, foi aluno de Milton Friedman e, em 1957, obteve o título de doutor em economia. Em 1958 passou três meses no Centro de Estudos Internacionais (Cenis) no Massachusetts Institute of Technology (MIT), onde conheceu Walt Whitman Rostow. Gradualmente, Frank se aproxima da antropologia, chegando cada vez mais à conclusão de que os fatores de desenvolvimento econômico eram, sobretudo, sociais e políticos. A Revolução Cubana abalou profundamente Frank, fazendo com que abandonasse o cargo de professor assistente na Universidade de Michigan e seguisse para o mundo subdesenvolvido com objetivo de construir uma visão no teatro de operações (Frank, 1991).

Ao contrário de seus colegas dependentistas, Frank se estabelece na UnB como professor visitante. Assim, na condição de instrutores, Marini, Dos Santos e Bambirra foram seus alunos no já mencionado curso sobre funcional-estruturalismo.

De acordo com Marini, ainda que Frank já possuísse um pensamento inquieto e original, foi somente na UnB que absorveu os novos elementos teóricos que surgiam na Nova Esquerda Revolucionária brasileira - mais especificamente da Polop - os quais o levariam a esboçar suas primeiras teses ainda em Brasília (Marini, 2005: 66). Dois ensaios são importantíssimos para essa mudança de rumo: "Sociologia do 
desenvolvimento e o subdesenvolvimento da sociologia", e também "A agricultura brasileira: capitalismo e o mito do feudalismo". Nas palavras do próprio Frank:

Estes trabalhos estavam direcionados, ao mesmo tempo, contra a teoria e a política do desenvolvimentismo derivada da - ou camuflada pela - teoria do desenvolvimento neoclássica e monetarista; contra as explicações keynesianas e estruturalistas; e contra a teoria, política e práxis da Cepal, da Aliança para o Progresso e dos partidos comunistas e marxistas ortodoxos. Coloquei todos no mesmo saco. Porque pesem suas diferenças, todos compartilhavam a visão de que o subdesenvolvimento era original ou tradicional. Todos postulavam que o desenvolvimento poderia ter lugar através de reformas graduais em sociedades e/ou economias duais, donde o setor moderno se expandiria e eliminaria o setor tradicional (Frank, 1991: 35).

O primeiro ensaio já traz a marca das inversões tão características do estilo frankiano, "Sociologia do desenvolvimento e o subdesenvolvimento da sociologia", e representa uma espécie de acerto de contas com o seu passado estrutural-funcionalista. Suas críticas ácidas atingem diretamente os seus velhos amigos de Chicago, como Bert Hoselitz, e também alguns conhecidos do MIT, como Walt Rostow. Seus alvos declarados são as teorias dos padrões de variáveis neoparsonianas e da mudança cultural e psicológica neoweberiana. A introdução ao texto é direta:

Submetida à análise crítica, esta nova sociologia do desenvolvimento mostra-se empiricamente nula quando confrontada com a realidade, teoricamente inadequada em termos de suas próprias normas clássicas sociocientíficas, e ineficaz em seu propósito de levar a cabo suas supostas intenções de promover o desenvolvimento dos países subdesenvolvidos (Frank, 1973: 35).

O texto ainda denuncia que estas teorias sociológicas comumente protegidas sob o manto da neutralidade axiológica universitária, na realidade serviram (e, diríamos, ainda servem) inúmeras vezes à Central de Inteligência Americana (CIA) e ao Departamento de Estado Norte-Americano (Frank, 1973: 42-44). Não seria ousado conjecturar o fato de que este ensaio tenha se fundamentado no curso preparado para os instrutores na UnB sobre o funcional-estruturalismo norte-americano.

O segundo ensaio - "A agricultura brasileira: capitalismo e o mito do feudalismo" - nos parece mais interessante, pois, ainda que reflita menor nível de maturidade teórica, esboça a tese do desenvolvimento do subdesenvolvimento:

Este ensaio sugere que as causas e a explicação da crise agrícola não devem ser buscadas no feudalismo e, sim, no próprio capitalismo. A economia do Brasil, inclusive a agricultura, é parte do siste- 
ma capitalista. A evolução deste sistema produz desenvolvimento e subdesenvolvimento ao mesmo tempo e explica a terrível realidade que vive a agricultura no Brasil e em outros países (Frank, 2005: 37, grifos nossos).

Seu objeto inicial de crítica é o dualismo estrutural, coincidente com ensaio anterior. Todavia, este objeto da crítica traz em si a influência do ambiente político-intelectual brasileiro: dos embates tanto à esquerda como à direita sobre a caracterização da economia e da sociedade brasileiras entre feudal, semifeudal ou definitivamente capitalista, como também sobre a natureza da revolução, nacional-democrática ou socialista. Tanto é assim, que, após analisar a estrutura comercial monopolista da agricultura brasileira, sua maior capitalização, ao tempo em que aumenta a produtividade e introduz técnicas mais modernas aprofunda a concentração de terras, amplia a inflação dos preços dos alimentos e a oferta de força de trabalho para as cidades, o que traduz justamente sua estrutura capitalista-mercantil e não um suposto feudalismo, o que constitui a contradição central no Brasil. Frank conclui, portanto, que

O Brasil, em seu conjunto, por mais feudais que suas características possam parecer, deve sua formação e sua natureza atual à expansão e ao desenvolvimento de um único sistema mercantil-capitalista que alcança (hoje com exceção dos países socialistas) o mundo inteiro. [...] este sistema capitalista, em todo tempo e lugar - e é de sua natureza que assim seja -, produz desenvolvimento e subdesenvolvimento. Um é tão produto do sistema "capitalista" como o outro. [...] Chamar "capitalista" ao desenvolvimento e atribuir o subdesenvolvimento ao "feudalismo" é uma incompreensão séria que conduz aos mais graves erros políticos (Frank, 2005: 58).

Ainda que não encontremos a categoria dependência, vemos o esboço do desenvolvimento do subdesenvolvimento, a crítica às concepções dualistas e a originalidade do subdesenvolvimento, a imperiosidade da análise integrada entre o interno e o externo para a compreensão mais adequada do desenvolvimento capitalista brasileiro, como também os equívocos políticos resultantes das imprecisões teóricas, todas concepções gestadas durante sua passagem pela Universidade de Brasília e de seus contatos dos embates políticos no âmbito da Nova Esquerda brasileira. 
Ruy Mauro Marini:

a UnB e o prelúdio de

subdesenvolvimento e revolução

Ruy Mauro Marini inicia sua formação acadêmica em 1956, na Escola Brasileira de Administração Pública da Fundação Getúlio Vargas, com uma passagem de dois anos no Instituto de Estudos Políticos da Universidade de Paris, o SciencesPo. Ao regressar ao Brasil, em 1960, Marini integra o grupo fundacional da Polop, mas também desenvolve intensa atividade jornalística na Prensa Latina e em O Metropolitano, e aos 30 anos fora integrado como instrutor à UnB, em setembro de 1962, por meio de indicação de Theotônio dos Santos. Em 1963, já passa à condição de professor assistente. Assim como Dos Santos, suas relações com o sociólogo Alberto Guerreiro Ramos foram fundamentais para a elaboração de um pensamento crítico e aberto.

Sobre a Universidade de Brasília, Marini é bastante generoso com a experiência, oferecendo um relato rico sobre sua passagem:

\footnotetext{
Uma das experiências mais ricas da minha vida acadêmica, já como docente, lecionando com Victor Nunes Leal, Lincoln Ribeiro e Theotônio dos Santos, as cadeiras de Introdução à ciência política e Teoria política, a nível de graduação, e codirigindo o seminário de pós-graduação sobre Ideologia brasileira; já como estudante, preparando minha tese de doutorado sobre o bonapartismo no Brasil (cujo texto e materiais se perderiam em 1964, quando da primeira invasão da Universidade pelo Exército); já participando das atividades diversas que a Universidade promovia, tanto internamente como no plano da extensão; já, finalmente, convivendo com os colegas já mencionados, além de outros -como André Gunder Frank, que ali aportou em 1963 (Marini, 2005: 65-66).
}

Como já referido, Marini considera fundamental as concepções da Nova Esquerda para a formação da teoria marxista da dependência, e reitera o fato de que seu desenvolvimento inicial tenha se dado na primeira metade dos anos 1960, no Brasil, que essa confrontação ideológica assumiu perfil mais definido e que surgiram proposições importantes para a abertura do caminho de uma elaboração teórica, capaz de enfrentar e, a seu tempo, derrotar a ideologia cepalina. Mas reconhece que seu amadurecimento teórico só viria após o golpe civil-militar de 1964, momento em que a jovem intelectualidade militante encontraria tempo para se dedicar plenamente ao trabalho acadêmico, e se veria convocada a isso pela situação imperante em toda a América Latina assolada pela contrarrevolução. Portanto, no começo da década de 1960, 
a teorização encontrava-se ainda estreitamente ligada ao combate político e os êxitos ou fracassos se mediam através de indicadores muito concretos (Marini, 2005: 67).

É possível encontrar uma série de artigos publicados por Marini entre 1958 e 1964, todavia, são textos em grande parte de caráter jornalístico ou militante. Seu primeiro trabalho de envergadura só vem a público em abril de 1965, "Contradicciones y conflitos en el Brasil contemporáneo", veiculado pela revista mexicana Foro Internacional. Ainda que seja uma produção vinculada a seu primeiro exílio mexicano, ela é intimamente relacionada à sua trajetória polopista e brasiliense. Isso por dois motivos: primeiro porque a temática do artigo envolve a reciprocidade dialética entre as estruturas de poder político e econômico, com foco para o fenômeno bonapartista (objeto da dissertação de mestrado destruída pelo golpe de 1964); segundo, foi amplamente baseado no relatório sobre a situação política brasileira apresentado na última reunião do comitê central da Polop, em março de 1965.

Não é possível avaliar o artigo em toda sua profundidade, portanto, nos limitaremos aos aspectos relativos à formação da teoria da dependência, deixando de fora a rica análise histórico-política do texto. $\mathrm{O}$ artigo se esforça por ampliar as bases explicativas do processo brasileiro pós-1930, principalmente em não limitar o golpe civil-militar de 1964 à mera correia de transmissão dos interesses dos Estados Unidos no país, como simples fator exógeno observável pela maior presença pós-1964 de capitais provenientes daquele país no Brasil. Logo nos primeiros parágrafos lemos que

num mundo caracterizado pela interdependência, quiçá pela integração, ninguém nega a influência dos fatores internacionais sobre as questões internas, sobretudo quando se está em presença de uma economia das chamadas "dominantes" ou "metropolitanas" e um país subdesenvolvido (Marini, 1965: 511).

Tal como os trabalhos de Dos Santos e de Frank, Marini também não utiliza a categoria dependência, encontramos mesmo referência ao latifúndio exportador como "sistema semicolonial de exportação" (Marini, 1965: 516), todavia, o texto já traz parte do método de análise característico desta corrente ${ }^{14}$ : a forma de integração subordinada de um país subdesenvolvido ao sistema capitalista mundial, a dependência como relação de dominação e exploração entre países formalmente independentes e, no âmbito do país dependente, entre as classes sociais, articulando assim os níveis externos e internos da análise. De modo que, para Marini, a explicação das políticas de industrialização para a substituição de importações, no Brasil, ainda que possua suas características nacionais específicas, tem de ser integrada às crises e à desorganização temporária do sistema capitalista mundial (1914-1918,
14. Isso nos parece muito procedente, uma vez que este artigo associado a um segundo texto, também de 1965 - "Brazilian interdependency and imperialist integration" -, fornecerão a síntese para a "Dialética do desenvolvimento capitalista brasileiro", texto que irá compor seu clássico sobre a teoria marxista da dependência, Subdesenvolvimento e revolução, de 1967. 
depois entre 1929-1932 e 1939-1945). E a estrutura específica do desenvolvimento do capital industrial no país, sinônimo de desenvolvimento econômico, faz com que os interesses da nascente burguesia industrial nunca sejam definitivamente separados daqueles relativos ao latifúndio exportador - desde as relações de produção-consumo, até a demanda de divisas para importação de bens de capital -, como também do capital estrangeiro. Essa simbiose de interesses fez com que, por volta dos anos 1960, o capitalismo dependente entrasse em sua primeira crise estrutural, quer dizer, sem relação direta com qualquer crise internacional, levando aos limites qualquer esforço reformista (Marini, 1965: 522).

Os dois esforços de instalação de um governo civil forte - primeiro o bonapartismo carismático de Jânio Quadros, em 1961, e depois o bonapartismo de massas de João Goulart -, representam a última aposta no bloco dominante na contenção do movimento popular que, desde fins dos anos 1950, crescia vertiginosamente. A saída do bonapartismo militar foi a maneira de resguardar o sistema de exploração estruturado na reciprocidade de interesses da burguesia industrial nacional, do capital imperialista e do setor latifundiário exportador. Como conclusão, o texto deixa claro o abandono da burguesia nacional de qualquer pretensão ao desenvolvimento capitalista autônomo, e que tal papel de sócio menor do capital estrangeiro que levava à maior capitalização da indústria tinha como consequências rebaixar ainda mais o nível de vida popular e concentrar ainda mais os capitais dispersos entre a pequena e média burguesia nas mãos do grande capital. Para Marini já estava claro que não se trataria de um episódio exclusivo ao Brasil, mas de uma tendência confirmada na América Latina, principalmente no Cone Sul. Fato provado pelo golpe cívico-militar argentino em 1966.

\section{Reconsiderando as ciências sociais na Universidade de Brasília}

O leitor interessado na teoria marxista da dependência sabe que está aberta a discussão sobre a produção de quatro de seus principais intelectuais que trabalharam durante dois anos na Universidade de Brasília. Este artigo introduz o debate sobre a produção de ideias e sobre o desenvolvimento da teoria neste ambiente universitário, empregando análise de documentos, entrevistas e memoriais dos próprios autores, o que leva à reflexão de que houve sim um papel insubstituível desempenhado durante o período de trabalho como instrutores e como professor (no caso da André Gunder Frank) da Universidade de Brasília. As ideias se entrelaçam com as condições materiais circundantes, daí a importante e incontornável influência político-teórico da Polop para a elaboração do novo enfoque das ciências sociais. Empregamos a metáfora de raízes para designar este papel na formulação da teoria 
da dependência, para evidenciar elementos que contribuíram para lançar bases à teoria. Por um lado, André Gunder Frank defende vigorosamente o papel da Universidade não só como fonte, mas como unidade de participação no desenvolvimento da teoria mesmo, posição em que é secundado por Theotônio, enquanto os demais - Vânia e Ruy Mauro - pendem para a construção da teoria no Chile e no México. A questão, em nosso entender, não deve ficar apenas em opiniões, pontos de vista, avaliações e sim buscar elementos concretos para embasar as hipóteses.

A universidade, como eminente espaço crítico, propiciou que fosse travado um vigoroso embate, inicialmente metodológico, entre as grandes correntes do funcionalismo e do marxismo nas ciências sociais. Este embate tomou lugar por meio de seminário e de curso realizados na Universidade de Brasília por André Gunder Frank. Posteriormente, este choque se projetou na discussão entre weberianismo e marxismo que está na base das duas correntes que daí procederam na análise das relações entre países por meio das categorias de dependência e de interdependência.

Por outro lado, o grupo que empregava mais a metodologia e a teoria marxista para o desenvolvimento da análise e para a pesquisa, procurou reforçar suas proposições conceituais e teóricas mediante a realização de um grupo de estudo aberto de leitura de $O$ Capital, que alcançou grande interesse de outros instrutores e professores da Universidade de Brasília. Relatos apontam para brevidade da existência do grupo de leitura por força do golpe de Estado o que teria impedido o desenvolvimento de categorias cruciais, tal como a superexploração ou exploração redobrada, conforme aparece nas bases da teoria da dependência.

Outro elemento importante durante a estada na Universidade de Brasília consiste no curso realizado pelo Ilpes sobre desenvolvimento e subdesenvolvimento, que possibilitou o debate sobre as condições do subdesenvolvimento como inseparáveis do movimento do capitalismo mundial. Este debate contemplava a ideia de uma dupla redobrada exploração dos trabalhadores, primeiro pelas empresas multinacionais e segundo pelas empresas nacionais. Entretanto, o elo da dependência por meio da sobre-exploração dos trabalhadores pela via do pagamento do salário abaixo do valor da força de trabalho como mecanismo que as empresas nacionais empregavam para compensar o retirada dos valores produzidos nos países dependentes pelo capital internacional, transformando o fundo de consumo num fundo de acumulação, não encontramos evidência empírica concreta de que tenha sido elaborado durante o período de docência e pesquisa na Universidade de Brasília. Outras condições de pertença a Universidade de Brasília que também contribuíram ou não com a teoria da dependência, tais como a liberdade e a autonomia no desenho dos programas 
das disciplinas, o trabalho de pesquisa coletiva com os estudantes e textos escritos produzidos localmente àquela época requerem continuada investigação, dada a condição inicial deste artigo de suscitar temas para o debate. Além do papel da universidade, entendemos que é importante buscar as raízes políticas do engajamento dos intelectuais com a organização Polop para o desenvolvimento pleno da teoria da dependência.

Abstract: It is proposed in this paper to study the contribution of four intellectuals, who worked in the beginnings of the University of Brasilia, Brazil, to the marxist theory of dependency. Texts and memorials written by them as well as two interviews recently made are used as sources of information, besides the usual bibliography about the subject matter. Evidence was found that the University of Brasilia has been the place for theoretical disputes between structural functionalism and marxism, for the need to lay foundations for the analytical production of these intellectuals with the methodological and theoretical contributions of marxism, for making the criticism of the conceptions of the relations between countries that are part of the world system as developed and underdeveloped, without implicating a relation of exploitation among them, while the references of a general formulation of the theory of dependency were more as roots and beginnings, there including the mechanism of a double exploitation, either by the national bourgeoisies or by the international capitals. The paper indicates the militant formation of at least three of the four intellectuals in the ranges of Polop (Marxist Revolutionary Organization - Proletarian Politics) and its influence over political action and over the need of a socialist revolution,

Keywords: marxist dependency theory, development, underdevelopment, Empire, University of Brasilia.

\section{Referências}

BAMBIRRA, Vânia. La mujer chilena en la transición al socialismo. Punto Final, n. 133, p.1-8, Jun. 1971.

. Diez años de insurrección en América Latina. In. (Comp.). Diez años de insurrección en América Latina. v. 1. Santiago: Prensa Latinoamericana, 1972.

— Teoría de la dependencia: una anticrítica. Ciudad de México: Era, 1983.

- Teoria da dependência. Lugar e papel das ciências sociais da UnB. Brasília: Biblioteca do Instituto de Ciências Sociais, p. 27-71. II- Entrevista com Vânia Bambirra, concedida a Sadi Dal Rosso, em 18 Out. 2013.

BLÖMSTROM, Magnus; HETTNE, Bjorn. Development theory in transition. The dependency debate and beyond: third world responses. London: Zed Books, 1984.

Dos Santos, Theotônio. Quais são os inimigos do povo? Rio de Janeiro: Civilização Brasileira, 1962. 
—. Dependencia y cambio social. Buenos Aires: Amorrortu Editores, 1973.

_. Democracia e socialismo no capitalismo dependente. Petrópolis: Vozes, 1991.

—. Memorial. Niterói, 1994 (mimeo).

- Teoria da dependência. Lugar e papel das ciências sociais da UnB. Brasília: Biblioteca do Instituto de Ciências Sociais, p. 3-24. I- Entrevista com Theotônio dos Santos, em 18 Out. 2013.

- Teoria da dependência. Lugar e papel das ciências sociais da UnB. Brasília: Biblioteca do Instituto de Ciências Sociais, p. 3-24 III - Palestra de Theotônio dos Santos, realizada em 2013, no Departamento de Sociologia da UnB.

FRANK, André Gunder. La sociología del desarrollo y el subdesarrollo de la sociología. In: — (Org.). América Latina: subdesarrollo o revolución. México: Era, 1973.

- El desarrollo del subdesarrollo: un ensayo autobiográfico. Caracas: Nueva Sociedad, 1991.

— . A agricultura brasileira: o capitalismo e o mito do feudalismo. In: STÉDILE, João Pedro (Org.). A questão agrária no Brasil. v. 2. São Paulo: Expressão Popular, 2005.

KAY, Cristóbal. Latin American theories of development and underdevelopment. London: Routledge, 1989.

LARRAIN, Jorge. Theories of development. Capitalism, colonialism and dependency. Oxford: Polity Press, 1998.

LEAL, Leovegildo Pereira. História da Polop: alternativa marxista ao reformismo na esquerda brasileira. Pará de Minas: Virtual Books, 2014.

MARINI, Ruy Mauro. Contradicciones en Brasil contemporáneo. Foro Internacional, v. 5, n. 4, p. 511-546, Abr.-Jun. 1965.

- La izquierda revolucionária brasileña y las nuevas condiciones de la lucha de clases. In: BAMBIRRA, Vânia (Comp.). Diez años de insurrección en América Latina, v. 2. Santiago: Prensa Latinoamericana, 1971.

. Memória. In: STÉdILE, João Pedro; TRASPADINI, Roberta (Orgs.). Ruy Mauro Marini: vida e obra. São Paulo: Expressão Popular, 2005. 
MATTOS, Marcelo Badaró. Em busca da revolução socialista: a trajetória da Polop (1961-1967). In: RIDENTI, Marcelo; REIS FILHO, Daniel Aarão (Orgs.). História do marxismo no Brasil, v. 5. Campinas: Editora Unicamp, 2007.

MEYER, Victor. Frágua inovadora: o tormentoso percurso da Polop. In: Centro de Estudos Victor Meyer (Org.). Polop. Uma trajetória de luta pela organização independente da classe operária no Brasil. Salvador: Artetexto, 2009.

PALMA, Gabriel. "Dependencia y desarrollo: una visión crítica". In: SEERS, D. (Org.). La teoría de la dependencia: una revaluación crítica. Ciudad de México: Fondo de Cultura Económica, 1987.

ORGANIZAÇÃO REVOLUCIONÁRIA MARXISTA - POLÍTICA OPERÁRIA. Programa Socialista para o Brasil. In: Centro de Estudos Victor Meyer (Org.). Polop. Uma trajetória de luta pela organização independente da classe operária no Brasil. Salvador: Artetexto, 2009.

REIS FILHO, Daniel Aarão. Classe operária, partido de quadros e revolução socialista. O itinerário da Política Operária - Polop. In: FERREIRA, Jorge ; REIS FILHO, Daniel Aarão (Orgs.). As esquerdas no Brasil. v. 3. Rio de Janeiro: Civilização Brasileira, 2007.

SALMERON, Roberto A. A universidade interrompida: 1964-1965. Brasília: Editora UnB, 2007. 